\title{
Islamic perspective on end of life issues in persistent vegetative state patients - a case report
}

\author{
Mohammad Yousuf Rathor ${ }^{1}$ and Dr Che Rosle Draman ${ }^{1}$ \\ 'Department of Internal Medicine, Faculty of Medicine, International Islamic University Malaysia
}

\begin{abstract}
Persistent vegetative state (PVS) is a clinical condition of unawareness of self and environment with preserved sleep-wake cycles. Its clinical diagnosis can be a difficult unless a physician has adequate experience and expertise in evaluating neurological syndromes. Outcome is based on aetiology and age. Decisions on limiting life-sustaining treatment (LST) for these patients are emotionally and morally challenging. We present a case of a young boy who went into PVS following traumatic brain injury (TBI) with the aim to review some of the ethical issues regarding its management from Islamic perspective.
\end{abstract}

KEYWORDS: Ethics, Religion, End of life, vegetative state, Traumatic brain injury

\section{INTRODUCTION}

Traumatic brain injury (TBI) is one of the leading causes of death and disability especially among young people in their productive years of life. ${ }^{1}$ It results in major socioeconomic burden to the family members and friends close to the person who is injured. Patients who survive the acute insult in the intensive care unit can have progressive recovery and may progress from coma to a vegetative state (VS) and/or a minimally conscious state (MCS). ${ }^{2}$ Coma is a state in which a person cannot be awakened and does not respond to any stimulation including pain. Generally it lasts few days to a few weeks, after which some patients gradually recover, but some permanently lose all brain function (brain death), while others evolve to a vegetative state (VS). Patients in VS are unconscious and unaware of their surroundings, but they continue to have a sleep-wake cycle and can have periods of alertness. ${ }^{3}$ They are able to breathe spontaneously, retain their gag, cough, sucking, and swallowing reflexes. They often look fairly "normal" to families and friends who hope and pray for their full recovery.

Generally, when VS lasts more than one month, it is called persistent vegetative state (PVS). ${ }^{4}$ The diagnosis is primarily clinical, with repeated neurological examination over a period of time, with no evidence of awareness of self or environment. However recently neuroscientists have challenged whether all PVS patients have actually lost consciousness. ${ }^{5}$ Consequently, bedside examination

Corresponding author:

Mohammad Yousuf Rathor

Department of Internal Medicine,

Faculty of Medicine,

International Islamic University Malaysia,

Jalan Sultan Ahmad Shah,

25200 Kuantan,

Pahang, Malaysia

Email: rathor@iium.edu.my alone does not seem sufficient to make a reliable diagnosis and functional neuroimaging can offer a complimentary approach. Given these factors, misdiagnosis is common. ${ }^{6}$ Further PVS patients need to be differentiated from MCS patients who have a better prognosis. ${ }^{7}$ MCS patient are awake with minimal awareness to environmental stimulation consistent with the presence of cognitive function. Similarly "locked-in" syndrome a distinct condition in which patients are aware and awake, but cannot move or communicate due to complete paralysis of the body. They communicate through eye movement or blinks, which are not affected by the paralysis.

\section{Prognosis and treatment}

Once a patient has been treated for the initial brain injury or event, and PVS is established, effective interventions are limited to specialist rehabilitation and care aimed at preventing complications. They should receive appropriate medical, nursing, or home care to maintain their personal dignity and hygiene. Potential recovery is linked to the location, extent, age and nature of the brain damage. TBI tends to have a better outcome than non-traumatic aetiology (NTBI) (especially anoxia). These patients are said to be in permanent vegetative state, when the diagnosis of irreversibility can be established with a high degree of clinical certainty, a definition, based on probabilities, not absolutes. Traditionally, recovery from PVS more than a year after TBI and 6 months after a NTBI is regarded as highly improbable but not totally impossible. ${ }^{8}$ Once PVS is considered to be permanent, a "Do not resuscitate" (DNR) order is appropriate. Many of these patients live for months to years if provided with life-sustaining treatment (LST). LST can be defined as any treatment without which the patient would die within a foreseeable time frame. ${ }^{9}$ The withdrawal of LST from these patients is a controversial issue, as highlighted by public debates and several judicial decisions over the past 40 years. ${ }^{10-14}$ Such decisions are extremely 
challenging for medical care personnel as well as families. Decisions on their end of life (EOL) care should be made with reference to the patient's cultural, religious, or spiritual beliefs and best interests. ${ }^{15}$

We present a case of young boy who went into PVS following $\mathrm{TBI}$ and attempt to discuss the specific ethical aspects of managing it from an Islamic perspective.

Case Report: A 14 year old previously healthy Malay boy was admitted to our surgical intensive care unit (SICU) after a road traffic accident. His Glasgow Coma Scale (GCS) on arrival was 3/15. He was intubated and resuscitated following which his cardiovascular system resumed activity. Immediate computerized scan (CT) of the head revealed left tempo-parietal subdural haemorrhage and brain swelling. Following decompressive craniotomy and clot evacuation he showed cycles of sleep and wakefulness on day 3 after the accident. His general state was stable. He was discharged home in a PVS but was readmitted one week later due to aspiration pneumonia. He was resuscitated. Mother was told about the grim prognosis of her son. Due to prolonged ventilation, tracheotomy was suggested to which she consented. She also agreed to our suggestion not to resuscitate her son (DNR) in case of cardiac arrest as it would in fact only prolong his suffering. The Sharl'ah principle: "Harm must be eliminated but not by means of another harm" was used to justify it. ${ }^{16}$ The boy recovered from pneumonia and was able to breathe of his own. He was fully dependent for activities of daily living (ADL) and was discharged home with the advice to undergo regular physiotherapy, and follow-up at our rehabilitation clinic.

\section{Islamic perspective}

Currently there is no available treatment for PVS patients that would satisfy the efficacy criteria of evidence-based medicine. Regardless of its incurable or debilitating nature, it is never Islamically appropriate to take a patient's life for saving him/her from suffering. Islam emphasizes on the sanctity of life, "... if anyone killed a person, not in retaliation of murder, or(and) to spread mischief in the land, It would be as if he killed all mankind, and if anyone saved a life, it would be as if he saved the life of all mankind." ${ }^{17}$ On the other hand, it also emphasizes that our lives will end at a fixed, predetermined time that only Allah SWT knows, "It is not given to any soul to die, but with the permission of Allah at an appointed time." 18 These two basic Islamic beliefs will make the base to judge EOL decisions in PVS cases. Strict adherence to the doctrine of the sanctity of life would require family/carers to continue their maintenance, perhaps for many years. However, few would regard this as an appropriate choice when the person clearly has no likelihood of recovery. Therefore once the treating physicians are certain that the condition of a Muslim PVS patient is irreversible; treatment is futile, involve suffering to the patient and only delays the dying process, they are permitted to withhold or withdraw LST as it ceases to be mandatory. ${ }^{19}$ However, it should be a collective decision with the patient's family and all individuals involved in his care. According to Article 63 of the Islamic code of medical ethics, "the treatment of a patient can be terminated if a team of medical experts or a medical committee involved in the management of such patient are satisfied that the continuation of treatment would be futile or useless." In these situations, death is allowed to take its natural course. ${ }^{20}$ Further the Prophet Muhammad (saw) has said, "above all do no harm" and this rule of nonmaleficence is the cornerstone of all medical ethics. ${ }^{16}$ The initiation of artificial nutrition and/or hydration (ANH) is a form of medical treatment according to some Muslim jurists, as it involves medical procedures to preserve bodily strength. However once ANH has been initiated in the ICU, it must be continued as its withdrawal would in effect starve the patient and hasten his death. ANH may cause bloating in some patients as it is not processed in the same way as in a normal person. In that case if its burdens outweigh the benefit to the patient, it may be withheld or withdrawn, whether or not the patient will die as a result of this action. Prophet Muhammad (SAW) has discouraged forcing the sick to take food or drink. Furthermore physician must explain to the family members that a state of dehydration is beneficial to bed-bound patients and may actually stimulate the production of endorphins that help to contribute to a peaceful and comfortable death. ${ }^{21}$

\section{CONCLUSION}

Ethical dilemmas in managing PVS cases in previously healthy individuals confront everyone the patient, his/her family and the health care personnel and these issues by their nature are rarely resolvable to the satisfaction of all. It is the physician who must explain the patient's prognosis, the benefits and harms of specific interventions to the family/ surrogate and make appropriate decision in accordance with their Islamic values and beliefs. We must realize the fact that none of us are in a position to protect our loved ones from death once ordained from Allah swt.

\section{REFERENCES}

1. Roozenbeek B et al. Changing patterns in the epidemiology of traumatic brain injury. Nature Review Neurology. 2013; 9(4): 231-236.

2. Bernat JL. Chronic consciousness disorders. Annu Rev Med. 2009; 60: 381-92.

3. Schnakers C, Giacino J, Kalmar K, Piret S, Lopez E, et al. Does the FOUR score correctly diagnose the vegetative and minimally conscious states? Ann Neurol. 2006; 60(6):744745.

4. Jennett B \& Plum F. "Persistent vegetative state after brain damage: a syndrome looking for a name." Lancet. 1972; 1:734-37. 
5. Monti MM, Vanhaudenhuyse A, Coleman MR, et al. Willful modulation of brain activity in disorders of consciousness. N Engl J Med 2010; 362:579-89.

6. Schnakers C, Vanhaudenhuyse A, Giacino J, et al. "Diagnostic Accuracy of the Vegetative and Minimally Conscious State: Clinical Consensus versus Standardized Neurobehavioral Assessment. BMC Neurology 2009; 9: 35.

7. Giacino JT \& Zasler ND. "Outcome following severe brain injury: the comatose, vegetative and minimally responsive patient," J of Head Trauma Rehabilitation. 1995; 10(1):40-56.

8. Longo D, Fauci A, Kasper D, Hauser S. Harrison's Principles of Internal Medicine . 18 ed. New York: McGraw-Hill Professional; 2011.

9. Jox RJ . End-of-life decision making concerning patients with disorders of consciousness. Res Cogitans 2011; 1.

10. Luchetti M. Eluana Englaro, chronicle of a death foretold: ethical considerations on the recent right-to-die case in Italy. J Med Ethics 2010; 36:333-5.

11. MCFadden, Robert D. "FOCUS OF '76 RIGHT TO DIE CASE." The New York Times. The New York Times, 11 June 1985. Web. 09 Apr. 2016.

12. Right to Die” Justia Law. Justia, 2015. Web. 09 Apr. 2016.

13. Airedale NHS Trust v. Bland 1 All ER 821 (1993).

14. Kollas CD, Boyer-Kollas B. Closing the Schiavo case: an analysis of legal reasoning. J Palliative Med 2006; 9: 1145-63.

15. The Joint Commission. Advancing Effective Communication, Cultural Competence, and Patient- and Family-Centered Care: A Roadmap for Hospitals. Oakbrook Terrace, IL: The Joint Commission, 2010. http: // www.jointcommission.org/assets/1/6/ aroadmapforhospitalsfinalversion727.pdf.

16. Kamali MH. Qawa'id al-Fiqh: The Legal Maxims of Islamic Law. High Wycombe, England: The Association of Muslim Lawyers; 2006:3-4.

17. Ali YA. The meaning of the glorious Quran. Dar Al Kitab 1938; 5:32.

18. The Glorious Qur'an, Chapter 3, Verse 145

19. Padela A and Mohiuddin A. Ethical Obligations and Clinical Goals in End-of-Life Care: Deriving a Quality-of-Life Construct Based on the Islamic Concept of Accountability before God (Taklıf)," The American Journal of Bioethics, 2015; 15(1): 3-13.

20. Islamic Figh Assembly of the Muslim World League. Decision Number: 10/2. Makkah, Kingdom of Saudi Arabia: Oct 17th-21st, 1987.

21. Jericho BG, Morgenweck CJ (2009) End of life issues: withdrawal of life-sustaining therapy. Am Soc Anesthesiologists Newslett 73(9):24-25 